University of Nebraska - Lincoln

DigitalCommons@University of Nebraska - Lincoln

M. Eugene Rudd Publications

Research Papers in Physics and Astronomy

1988

The Rainbow and the Achromatic Telescope: Two Case Studies

M. Eugene Rudd

University of Nebraska - Lincoln, erudd@unl.edu

Follow this and additional works at: https://digitalcommons.unl.edu/physicsrudd

Part of the Physics Commons

Rudd, M. Eugene, "The Rainbow and the Achromatic Telescope: Two Case Studies" (1988). M. Eugene Rudd Publications. 44.

https://digitalcommons.unl.edu/physicsrudd/44

This Article is brought to you for free and open access by the Research Papers in Physics and Astronomy at DigitalCommons@University of Nebraska - Lincoln. It has been accepted for inclusion in M. Eugene Rudd Publications by an authorized administrator of DigitalCommons@University of Nebraska - Lincoln. 


\section{The Rainbow and the Achromatic Telescope: Two Case Studies}

\section{By M. Eugene Rudd}

From the history of science we can learn not only some science and some history, but also something about how science is done and how it interacts with technology.

The first case study chosen illustrates the development of an understanding of a phenomenon of nature-one that has been observed with awe and wonder for as long as man has walked the Earth, but has only been well understood in the last 200 years. Some of the greatest thinkers of all time have worked on the problems of the rainbow.

The second study shows how an important invention became possible only when nature was well enough understood. It also illustrates the interaction of science and technology, that is, between understanding and application.

\section{Science and Technology}

Both case studies involve an understanding of nature...which, after all, is precisely what science involves. While technology is as old as man, science is a relatively recent invention. It started with the Greeks in 600 B.C. ${ }^{1}$ when the philosopher Thales asked a new kind of question. Instead of asking "who?" (e.g., what gods were responsible for thunder and wind, for birth and death, and for all the many forces of nature). Thales asked "how?" and that started man looking for physical causes instead of mythological explanations.

Science and technology are distinguished primarily by their motivation. Technology is mankind's attempt to solve the problems imposed on him by nature. He must deal with the problems of hunger, disease, the need for shelter and transportation, etc. Technology grew out of the tradition of the craftsman, the artisan, and the inventor.

Science, on the other hand, is motivated by the desire to understand. Building a boat to get across a river is a technological problem, but understanding the principles of buoyancy is a scientific problem. Science arose instead from the tradition of the prophets and the philosophers.

Science and technology interact to the benefit of both. Sometimes an invention or new technological advance triggers discoveries and advances in science. For example, the invention of the vacuum pump by von Guericke in about 1650 led to Robert Boyle's study of the relation of pressure and volume of a gas and, ultimately, to the ideal gas law. After the spectroscope

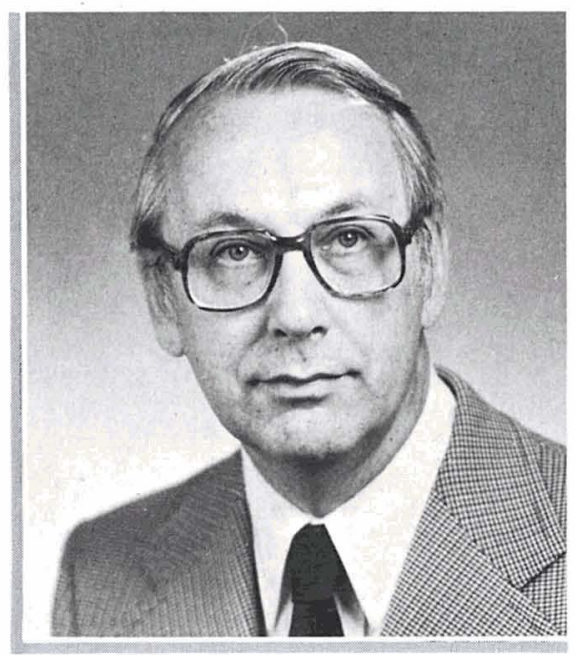

M. Eugene Rudd received his B.A. degree from Concordia College in Moorhead. Minnesota and his M.A. from the University of Buffalo. His Ph.D. is from the University of Nebraska where he has taught since 1965. In 1980 he was the chairman of the American Physical Society's Division of Electron and Atomic Physics. He has been interested in the history of optical instruments for about 12 years. 
was developed into a precision tool in the 19th century, its use in studying spectral lines eventually gave us much of our present information about atomic structure. The invention of the microscope was followed by the discovery of bacteria.

On the other hand, new understandings in science make possible inventions and whole new technologies. Maxwell's great theoretical work on the electromagnetic field made possible radio, radar, and television.

\section{The Rainbow}

Probably the earliest reference to the rainbow is in Genesis 9 where it says,

And God said "This is the sign of the convenant which I will make between me and you and every living creature that is with you for all future generations: I set my bow in the cloud, and it shall be a sign of the convenant between me and the earth. When I bring clouds over the earth and the bow is seen in the clouds, I will remember the convenant which is between me and every living creature of all flesh; and the waters shall never again become a flood to destroy all flesh.'

The "bow" is thought to be an archer's bow which God put away in the clouds since his anger had abated. This, of course, is a mythological story designed to describe man's relationship with God rather than to give an explanation of the phenomenon.

\section{Aristotle and Seneca}

Aristotle, who was an astute observer, noted in his Meteorologica that there was a secondary as well as a primary rainbow and also that rainbows could be observed in sprays of water. His explanation was based on the reflection of sunlight from clouds. ${ }^{2}$ In the first century A.D., Seneca said that the rainbow was an enlarged and distorted image of the sun formed by reflection from the clouds. He also noted that the colors seen in the rainbow were the same as those seen in light reflected from tiny pieces of glass. The explanations of Aristotle and Seneca possibly satisfied the people of that day, but could not begin to explain such things as the angles at which the bows appear, the greater intensity of light inside the bow compared to that outside, or, in fact, the presence of color itself.

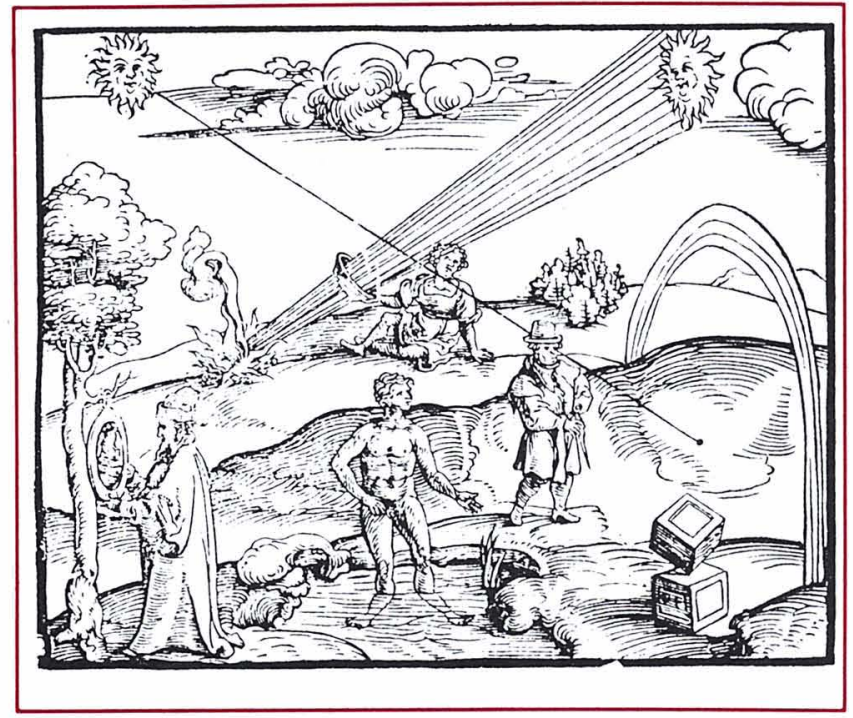

Fig. 1. Vitello's illustration of optical effects. Note that the rainbow on the right is centered on a point opposite the sun from the observer's eye. Woodcut from the 1535 edition of his book which was originally written in 1270 .

\section{Vitello and Theodoric}

In 1270 the Polish monk Vitello wrote one of the earliest treatises on optics, the study of light. Fig. 1 shows a woodcut from the 1535 edition of his book in which he illustrates reflection (the man with the mirror), refraction (the man standing in the water and a person with a burning glass), and the rainbow. The picture correctly shows that the rainbow is always seen opposite from the sun so that a line from the sun through the observer's eye goes to the center of the rainbow. Vitello realized that the rainbow involved refraction as well as reflection but he was not successful in finding the law governing refraction.

Another monk. Theodoric of Freiburg, Germany made a crucial forward step by pointing out that the refraction and reflection took place in each individual drop of water rather than from the entire cloud. ${ }^{3}$ He conducted experiments with glass bottles of water and correctly showed las illustrated in Fig. 2 showing one of his drawings from the year 1304) that the primary bow results from two refractions and one internal reflection. In another diagram he showed that the secondary bow 


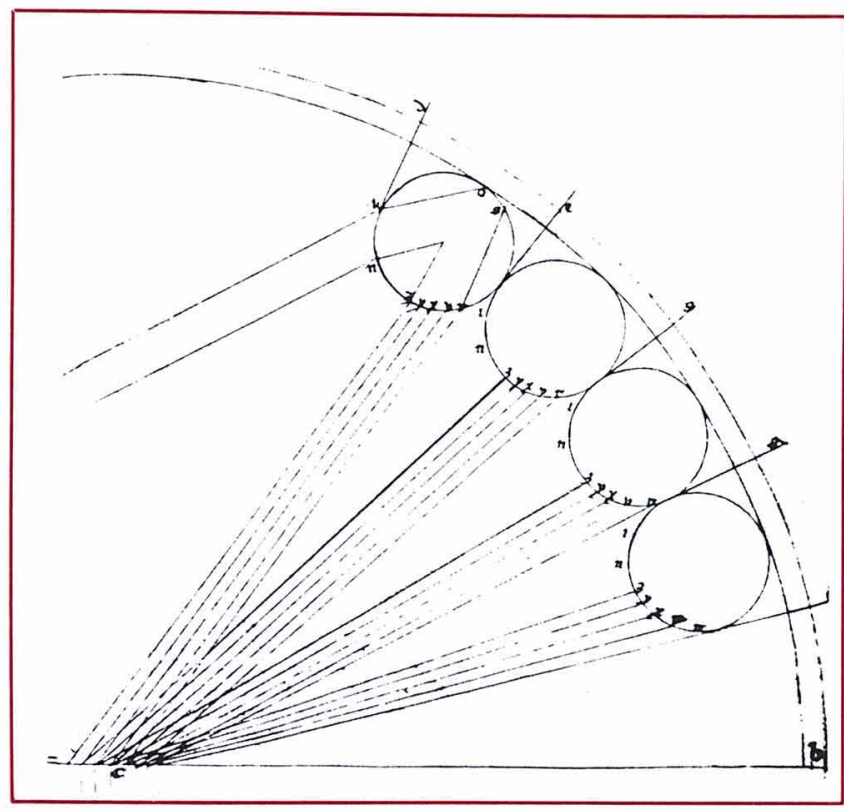

Fig. 2. Diagram explaining the rainbow drawn by Theodoric of Freiburg about 1304. He was the first to recognize that the rainbow resulted from refraction and reflection of light from droplets of water rather than from reflections from clouds.

results from two internal reflections and two refractions. But since the law of refraction was not known, he was unable to calculate the angles of the bows. It would be another three centuries before the next major step was made.

\section{Snell and Descartes}

Willebrord Snell who lived from 1591 to 1626 in Holland is generally credited with the discovery of the law of refraction, now called Snell's law. This relates the angle of incidence, $i$, to the angle of refraction, $r$. In modern terms, the ratio of the sines of these angles is a constant known as the index of refraction, $n$. That is, $\mathrm{n}=\sin \mathrm{i} / \sin \mathrm{r}$. However, this important law of nature remained unpublished until the French philosopher Rene Descartes made it available in 1637 in his Discourse on Method. ${ }^{4}$ (See Fig. 3.)

In the same book Descartes has a diagram, Fig. 4, of the rainbow in which he shows a ray $A B C D E$ which is reflected once inside a raindrop and another FGHIKE which is reflected twice, similar to Theodoric's explanation. By doing experiments with glass globes of water, Descartes discovered that the primary bow comes from drops for which the angle from the central point to the primary bow is $42^{\circ}$ and to the secondary bow is $52^{\circ}$. Using Snell's law, Descartes traced the directions of light through raindrops when the light encountered the drop at different angles. After tracing many rays he was able to show that regardless of where the light entered the raindrop, there was a maximum angle of the bow for a single internal reflection. Furthermore, he found that that angle was $42^{\circ}$.

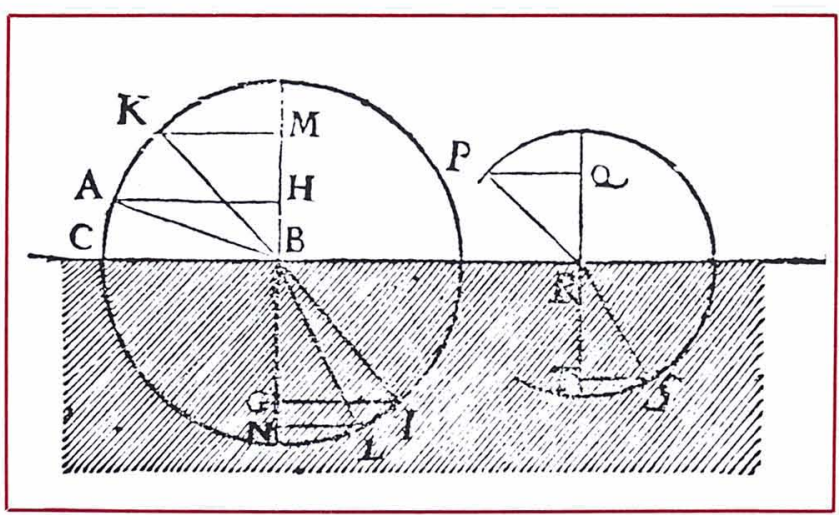

Fig. 3. Descartes' diagram with the first published statement of the law of refraction in 1637 . The ratio $\mathrm{KM} / \mathrm{NL}$ associated with the ray $\mathrm{KBL}$ is equal to the ratio $\mathrm{AH} / \mathrm{GI}$ associated with the ray $A B I$.

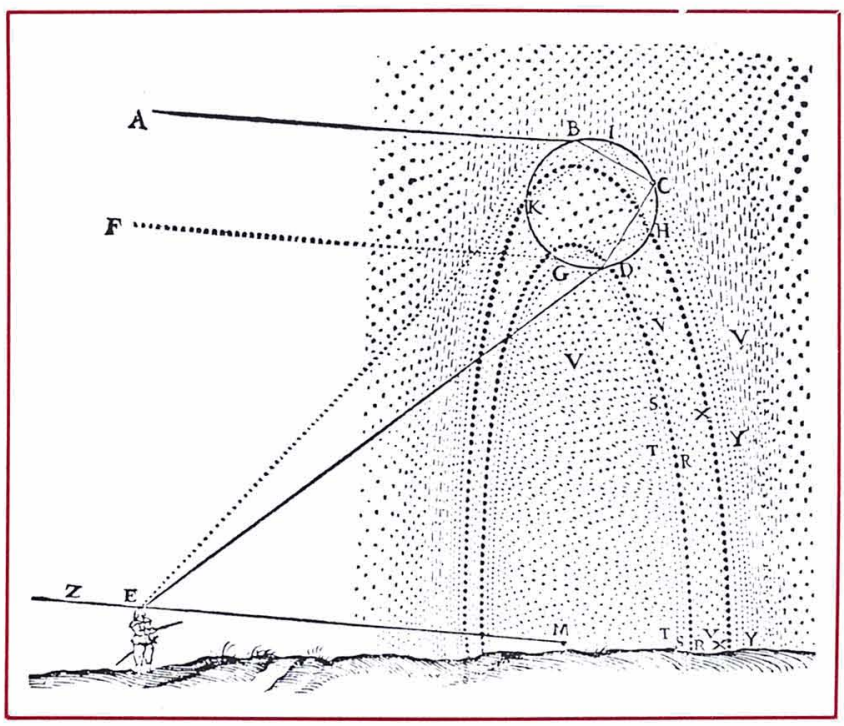

Fig. 4. Descartes' 1637 explanation of the rainbow. The primary bow is formed by ray $A B C D E$ making a single reflection. The secondary bow results from two reflections as in ray FGHIKE.

The presence of a maximum angle of observation of the rays can be seen in the diagram (Fig. 5) of three rays striking a raindrop at three different angles, $50^{\circ}, 60^{\circ}$, and $70^{\circ}$. The angle of refraction for each of these angles of incidence can be found from Snell's law and the law of reflection allows us to trace the ray the rest of the way. The result is that the observation angle first increases from $41^{\circ}$ to $42^{\circ}$ but then decreases again to $41^{\circ}$ as the angle of incidence is continuously increased. We also can do this mathematically. Doing a little geometry in Fig. 6, we get,

$$
\theta=4 r-2 i \text {. }
$$

Combining with Snell's law.

$$
\Theta=4 \sin ^{-1}(\sin \mathrm{i} / \mathrm{n})-2 \mathrm{i} .
$$

If we plot $\Theta$ vs. $i$, as in Fig. 7, we see that there is a maximum value of $\Theta$ which depends on the index of refraction. We find the maximum by using a little 


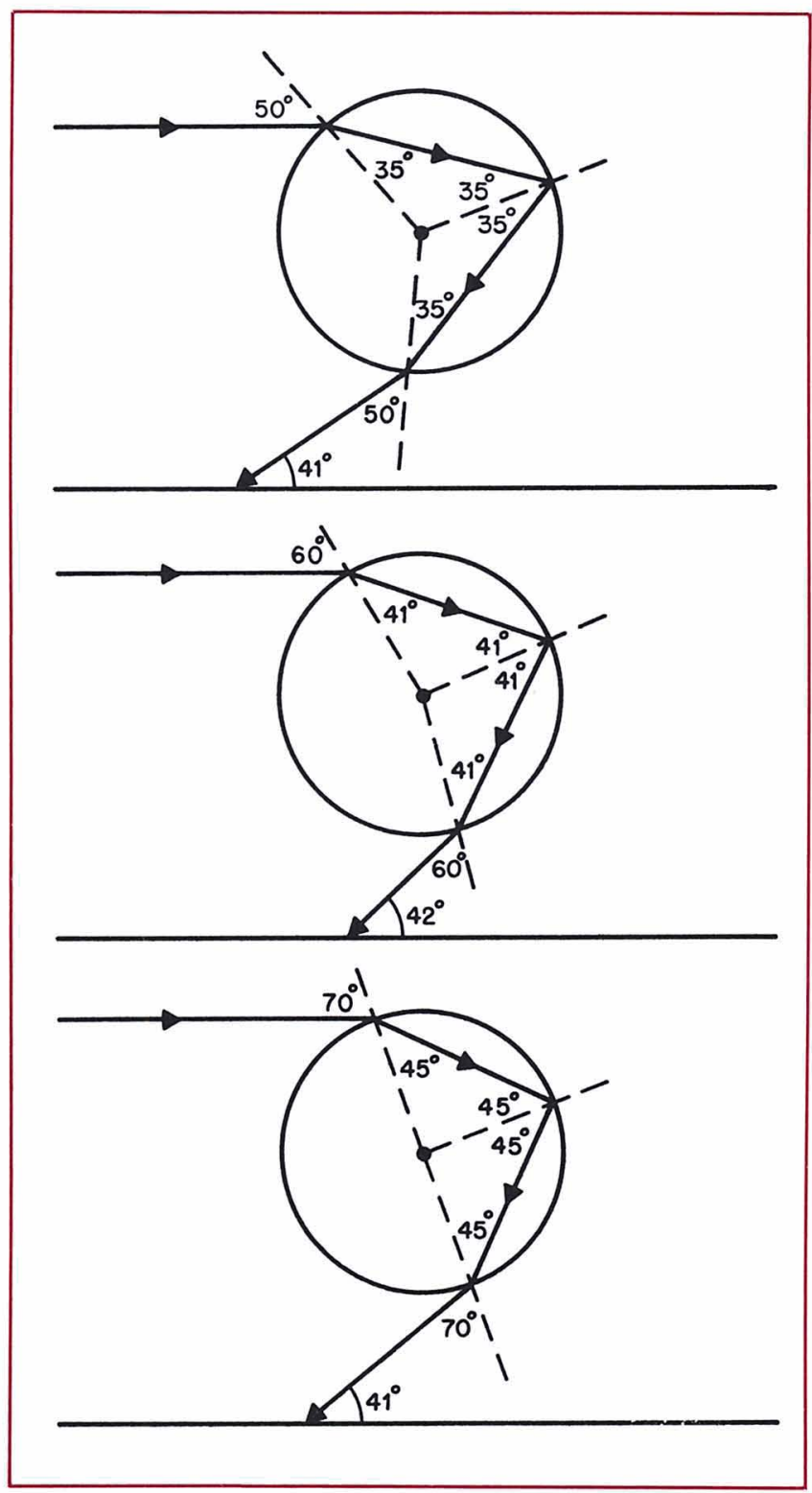

Fig. 5. Paths of rays incident on a water drop at $50^{\circ}, 60^{\circ}$, and $70^{\circ}$. The angle of the emergent ray increases from $41^{\circ}$ to $42^{\circ}$ and back again to $41^{\circ}$, indicating a maximum angle of deviation.

calculus:

$$
\mathrm{d} \theta / \mathrm{di}=0
$$

yields

$$
\sin \mathrm{i}_{\max }=\left|\left(4-\mathrm{n}^{2}\right) / 3\right|^{1 / 2} .
$$

Consulting the tables for indices of refraction of water,

\begin{tabular}{|c|c|c|c|}
\hline Wavelength & Color & $\mathrm{n}$ & $\Theta_{\max }$ \\
\hline $760 \mathrm{~nm}$ & Red & 1.3290 & $42^{\circ} 39^{\prime} 52^{\prime \prime}$ \\
\hline $380 \mathrm{~nm}$ & Violet & 1.3452 & $40^{\circ} 20^{\prime} 0^{\prime \prime}$ \\
\hline
\end{tabular}
we can construct the following table:

These angles agree well with the measured angles of the primary rainbow.

While it is not generally appreciated, Descartes' results

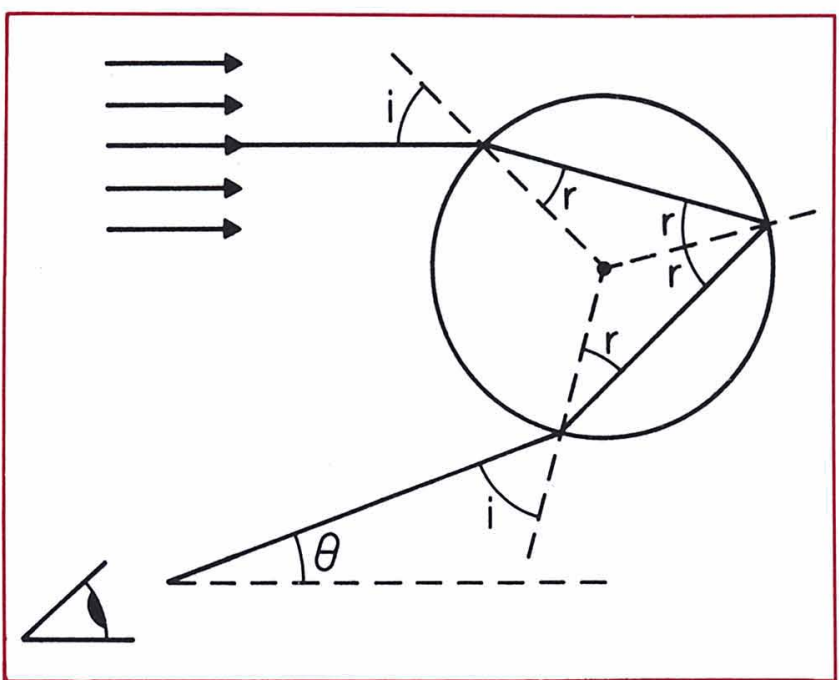

Fig. 6. Geometry of a ray making an internal reflection in a drop of water.

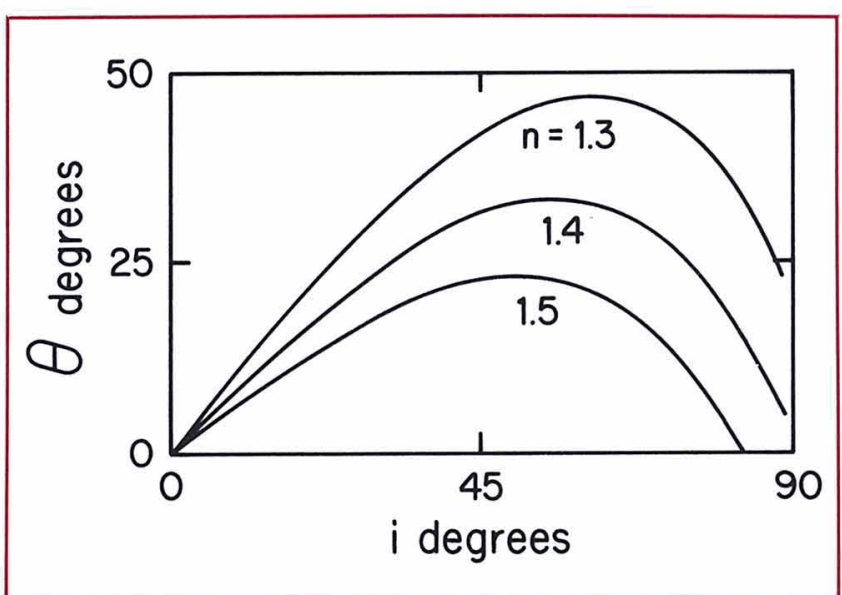

Fig. 7. Graph of the observation angle $\theta$ vs. the incident angle $i$ for light reflecting internally from spheres of different indices of refraction.

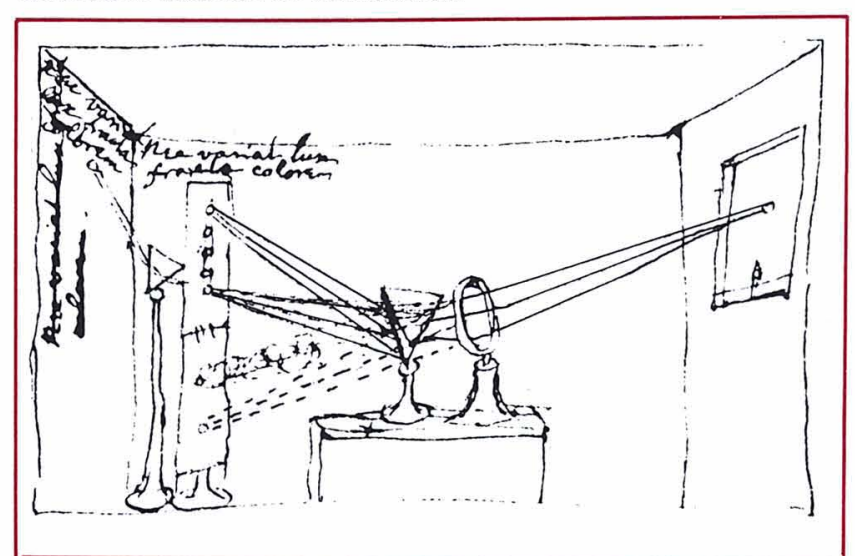

Fig. 8. Newton's own drawing of his prism experiment. In Latin he wrote, "Nor does the refracted light change color" (at the second prism).

showed that the rainbow actually consists of semi-circular disks of various colors of light which overlap and produce white or light gray inside the bow. Colors are seen only at the edge where, for example. the red disk comes at a slightly greater angle and 
therefore is not overlapped by the other colors. So, if someone put a big red filter over the sun, we would see a large semi-circular disk of red light, brighter at the rim, and dark beyond. This explains why the sky is lighter inside the rainbow than outside.

Descartes' explanation was fairly complete except that there was still no understanding of what produces the colors in the first place! That explanation was Isaac Newton's contribution.

\section{Newton}

While Newton was an undergraduate at Cambridge University, he did his famous experiments with a prism that were published six or seven years later. ${ }^{5} \mathrm{He}$ evidently did these experiments in his own room using a beam of sunlight that came through a small hole in his window shutter. The prevalent opinion at that time was that white light was "pure" and became colored by being modified when it passed through a prism or colored glass. Newton's experiments and interpretations showed instead that white light is a mixture of light of a continuous range of colors and, furthermore, that each color is refracted at a different angle by a prism.

Newton's first observation was that sunlight through a small hole in his shutter which passed through a prism formed an oblong spot on his wall rather than a circular spot as expected. He even gives its dimensions as 13" $\times 23 / 8^{\prime \prime}$. The width could be accounted for by the angular size of the sun but if white light were pure, the spot should not be elongated. He concluded that "light consists of Rays differently refrangible," meaning that they are refracted by different amounts and are therefore displaced. He then noted that the amount of refraction depended on the color of the light. Thus, in modern terms, the index of refraction depends on the color.

As shown in his own diagram in Fig. 8, Newton placed a board with a series of holes over the spectrum. Each hole allowed through one color of light. A second prism was placed behind the board. He wrote (in Latin) "Nor does the refracted light change color," meaning that the second prism does not form a new spectrum of colors when illuminated only by a single color of light from the first prism.

With Newton's account of the origin of colors, the explanation of the rainbow was essentially complete except for the phenomenon of supernumerary bows, a fringe-like set of colors seen on the edge of some rainbows. This was explained in 1804 by Thomas Young as a diffraction effect, but we will not discuss it here.

\section{The Invention of the Telescope}

Spectacles were invented by the 13 th century and the telescope in the early 17 th century. It seems strange that 400 years went by before a spectacle maker happened to glance through two lenses and discovered the principle of the telescope. Actually, there is some indication that knowledge of that principle was circulating. Robert Grosseteste, who was Roger Bacon's teacher, sometime in the first half of the 13th century wrote,

This part of perspective [i.e., the study of opticsl, if perfectly understood, shows us how to make very distant objects appear close, how to make nearby objects appear very small, and how to make a small object placed at a distance appear as large as we wish. so that it would be possible to read minute letters from incredible distances or count sand, seeds, blades of grass, or any minute objects. ${ }^{6}$

That sounds very much as if Grosseteste had looked through a telescope, but there is no evidence that he or anyone else actually had built a telescope at that time. There are several contenders for the title of inventor of the telescope, all of whom were spectacle makers in Middleburg, Holland. It is generally considered that Hans Lippershey was the first. In 1608 he requested a patent for such a device from the governing body of the Netherlands.' They replied by asking if he couldn't improve it so as to allow the use of both eyes. It wasn't enough that he invented the telescope, he had to invent binoculars as well! Even though he did later solve the problems involved in using both eyes, in the end instead of being given a patent, he was paid a sum of money for his telescope. Others were soon making telescopes and by 1609 they were being sold in Germany, England, and Italy.

\section{Galileo}

In May of 1609 a 45 -year-old professor of mathematics at Padua, Italy named Galileo Galilei heard about the invention and, after quickly studying the principles of refraction and optics, was able to construct a telescope of his own. ${ }^{8}$ He used a lead tube with a convex lens at one end and a concave lens at the other giving a magnifying power of 3 . Known today as the Galilean form of the telescope, it is used mostly for toy telescopes and opera glasses. Later he built a better one with a magnifying power of about 8 and finally, with great effort, one that magnified 30 times.

He showed his telescopes to many noblemen and senators who marvelled that they could see ships far out at sea well before they could be seen with the naked eye. They grasped the military advantage of being able to see the enemy before he saw them and also the commercial importance of being able to prepare for the arrival of a trading vessel before one's competitors. Thereupon, Galileo was rewarded with a new professorship and an increase of salary.

Galileo also turned his instrument to the heavens and made a number of important discoveries such as the mountains on the moon, the phases of Venus, the first four satellites of Jupiter, sunspots, and the fact that the Milky Way is composed of a multitude of faint stars.

These observations were ultimately of great importance in the overthrow of the idea of the Ptolemaic 


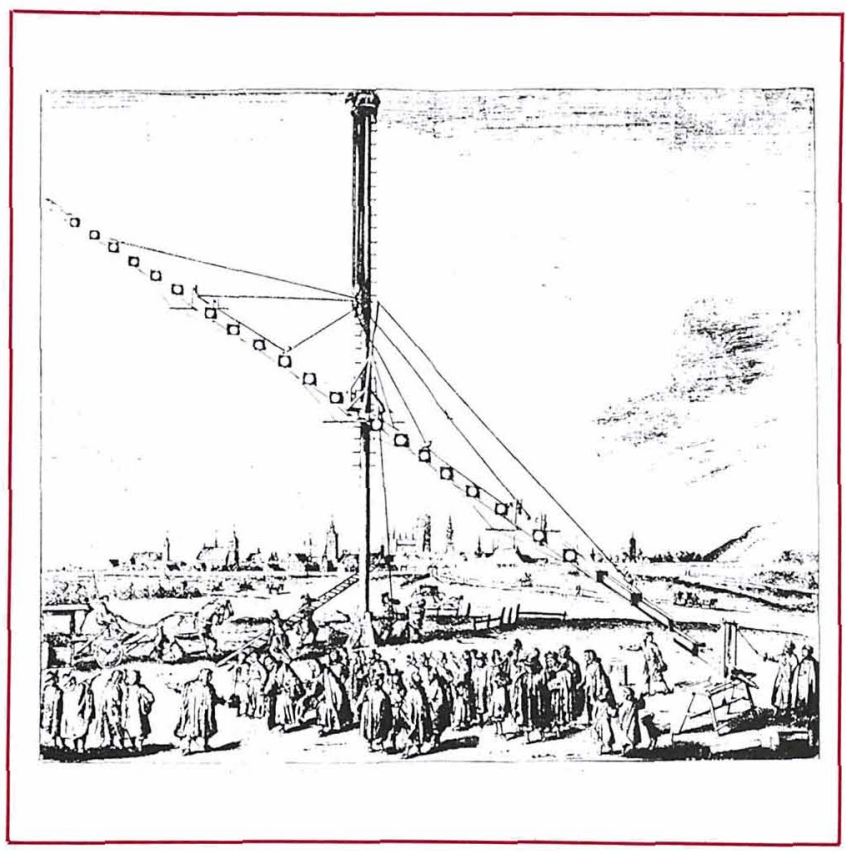

Fig. 9. Enormous telescope built by Hevelius in Danzig about 1650.

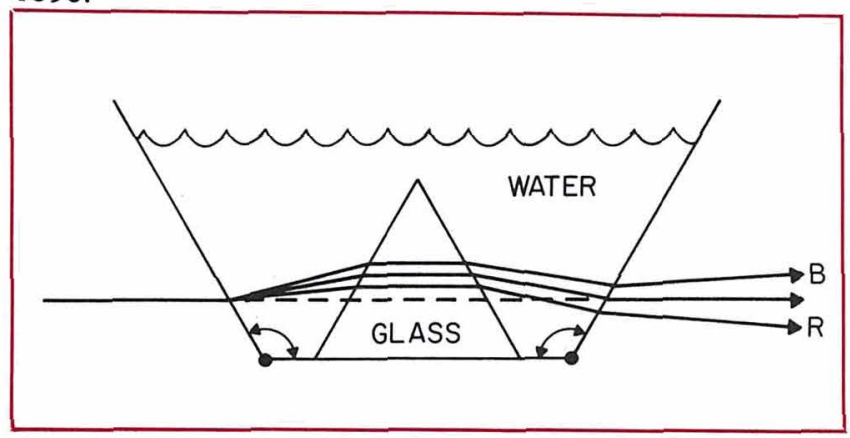

Fig. 10. Apparatus used by Newton and later by Dollond to see if refraction is always accompanied by dispersion. The angles of the walls of the trough could be varied.

picture of an Earth-centered universe and the Aristotelian idea of the distinction between the celestial and terrestrial laws of nature.

\section{Lens Aberrations}

When Galileo first presented his observations to the scientists of the day, however, they were largely rejected. Part of the reason was hard-headed stubbornness, but another reason was the poor quality of the images of the early telescopes. It was difficult in some cases to tell whether something seen in the telescope was real or due to a defect in the lens. Simple lenses, such as Galileo used, exhibited a number of aberrations. These were not defects in the figuring of the lens surfaces but were inherent in the nature of the glass and the nature of image formation by spherical surfaces. The two most important of these aberrations were spherical and chromatic aberration.

When using a lens with spherical surfaces, rays from an object going through the lens at different distances from the axis come to a focus at different points. One way to correct this is to grind the lens surface to non-spherical shapes, but lens makers of the 17 th and 18 th centuries were unable to do this. Another solution was to use lenses with a large ratio of focal length to diameter. Also, the longer the telescope the greater the magnifying power. This resulted in the building of longer and longer telescopes, such as the 150-ft instrument shown in Fig. 9 that was built by Hevelius of Danzig about 1650. Vibration, especially on windy days severely limited the usefulness of this telescope. Such enormously long telescopes were difficult to operate and had very small angles of view.

\section{Chromatic Aberration}

The other aberration results from the fact that glass (and all other transparent media) refracts different colors of light in slightly different directions. This, of course, is the phenomenon of dispersion which is responsible for the rainbow, as we have seen. Newton understood this and in his first published paper ${ }^{9}$ after he concluded that "light consists of Rays differently refrangible" he went on to say

When I understood this...I saw that the perfection of telescopes was hitherto limited not so much for want of Glasses truly figur'd according to the prescriptions of Optick Authors (which all men have hitherto imagined) as because that light itself is a Heterogeneous mixture of differently refrangible rays...Nay, I wonder'd, that seeing the difference in Refrangibility was so great, as I found it,

Telescopes should arrive to that perfection they are now at.

Since he knew that reflection was not subject to this aberration, he proceeded to build the first reflecting telescope.

The question came up, however, concerning the possibility of combining two lenses, one convex and the other concave, in such a way that the dispersion of the second, being in the opposite direction, would cancel out the dispersion of the first. Such a lens would be "achromatic," i.e., not chromatic.

In Newton's book Opticks ${ }^{10}$ he reported an experiment in which he caused a beam of white light to pass first through water, then through a glass prism, and again through water as shown in Fig. 10. He could vary the overall angle of refraction by tilting the sides of the trough. He noted that when the dispersion was zero, the deflection also was zero and an undeflected white light beam resulted. But when there was refraction, there was also a dispersion of the light into its colors. From this Newton concluded that dispersion always accompanied refraction and was always proportional to it. This meant that it was not possible to make a lens without chromatic aberration since a concave lens that would cancel the dispersion of the convex lens would also cancel its refraction. Such was the state of the subject when Newton died in 1727.

\section{Chester Moor Hall}

But sometimes even the best of us are wrong and 
Newton was wrong on this. Two years after his death a lawyer named Chester Moor Hall who liked to tinker with lenses, decided that an achromatic lens could be made using two lenses, provided that they were made out of different kinds of glass. ${ }^{11} \mathrm{He}$ was rather secretive about his idea so in 1733 he commissioned two different opticians, Edward Scarlett and James Mann, to each make one of the lenses. This way neither would suspect what he was doing. But, as luck would have it, both opticians were busy at the time and subcontracted the jobs to the same person, George Bass. When Bass learned that both lenses were for the same customer, he guessed what the purpose was and let out the secret to other opticians. Incredibly, nothing came of this. Either they didn't understand it or failed to recognize its importance.

\section{Euler, Dollond, and Klingenstierna}

In 1747 Leonhard Euler, a mathematician, wrote a paper suggesting the possibility of making a telescope objective in which the dispersion of one lens is balanced out by the opposite dispersion of a second lens. ${ }^{12}$ An English weaver named John Dollond. Fig. 11, liked to dabble in optics. He had a son, Peter, who was an optician. After reading Euler's paper, the elder Dollond took data from the reports of Newton's experiments, put them into Euler's equations, and showed that if there was a net refraction, there would also be a dispersion of colors. Since Newton was known to be a careful experimenter, this seemed to settle the matter. However, in 1755 a Swedish mathematician named Samuel Klingenstierna also read Euler's paper and said that the matter ought to be investigated further since Newton's results could be interpreted in a different way. Thereupon, John Dollond, who in the meantime had joined his son in the optical business, set up his own experiment similar to Newton's (Fig. 10) and got quite different results. ${ }^{13} \mathrm{He}$ was able to show that with a thin glass prism in water, he could find an angle of the vessel wall such that there was a net refraction, but no dispersion. He then tried two different kinds of glass and found that a $25^{\circ}$ flint glass prism and a $29^{\circ}$ crown glass prism gave the same refraction but different color divergences (Fig. 12.) This opened the way for him to make telescope objectives which were achromatic, as illustrated in Fig. 13. He applied for and received a patent for the achromatic lens in 1758. Recognizing the importance of his achievement, the Royal Society elected him a member and awarded him the Copley Medal. Dollond's optical business flourished, and for over a hundred years the Dollond firm was known for its high quality optical instruments. The company, in fact, still exists today but no longer makes telescopes.

In 1789 Peter Dollond attempted to explain the discrepancy between the results obtained by his father and by Isaac Newton. ${ }^{14}$ The latter, he surmised, used a prism made of glass from Venice which had a smaller

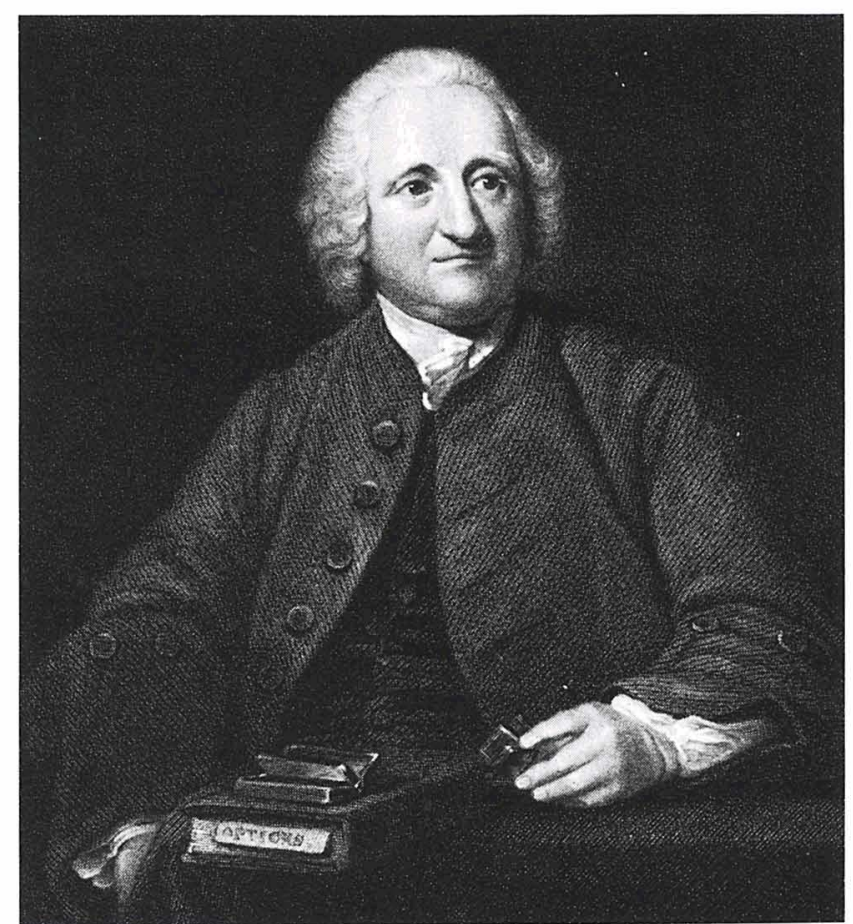

Fig. 11. John Dollond, English weaver who patented the achromatic lens in 1758 .

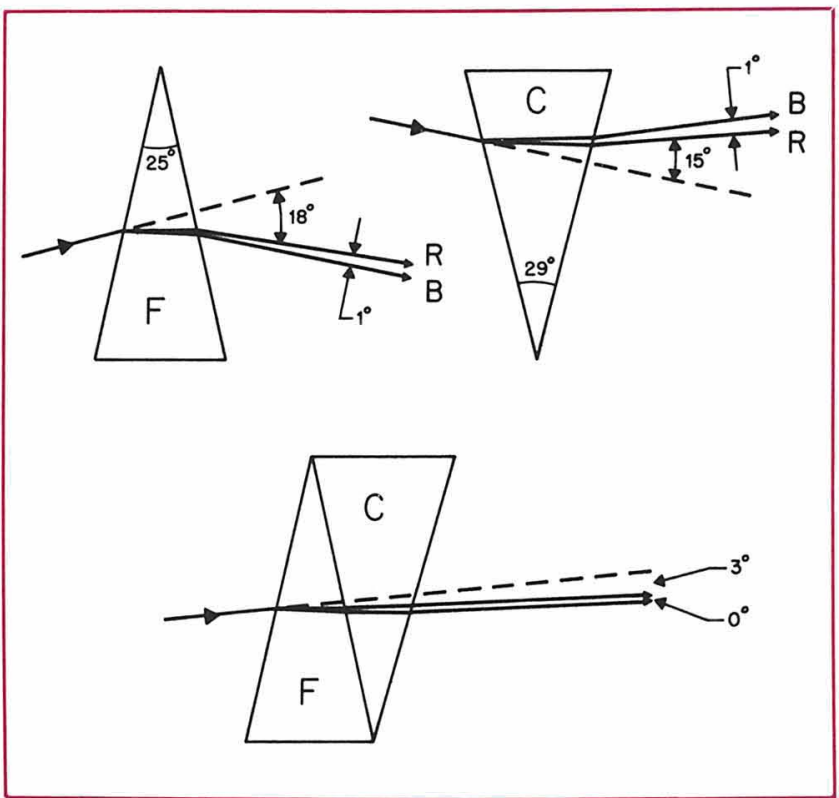

Fig. 12. Combinations of two prisms, one crown glass and one flint, which produce refraction, but no dispersion.

density than the common English glass used by Dollond. Presumably, the relation of the dispersion to the refraction for the Venetian glass was similar enough to that of water to give the results Newton obtained.

\section{Patent Litigation}

Other London opticians also had been experimenting with achromatic lenses and were themselves making achromatic telescopes, in violation of Dollond's patent. After the death of his father, Peter Dollond took a 

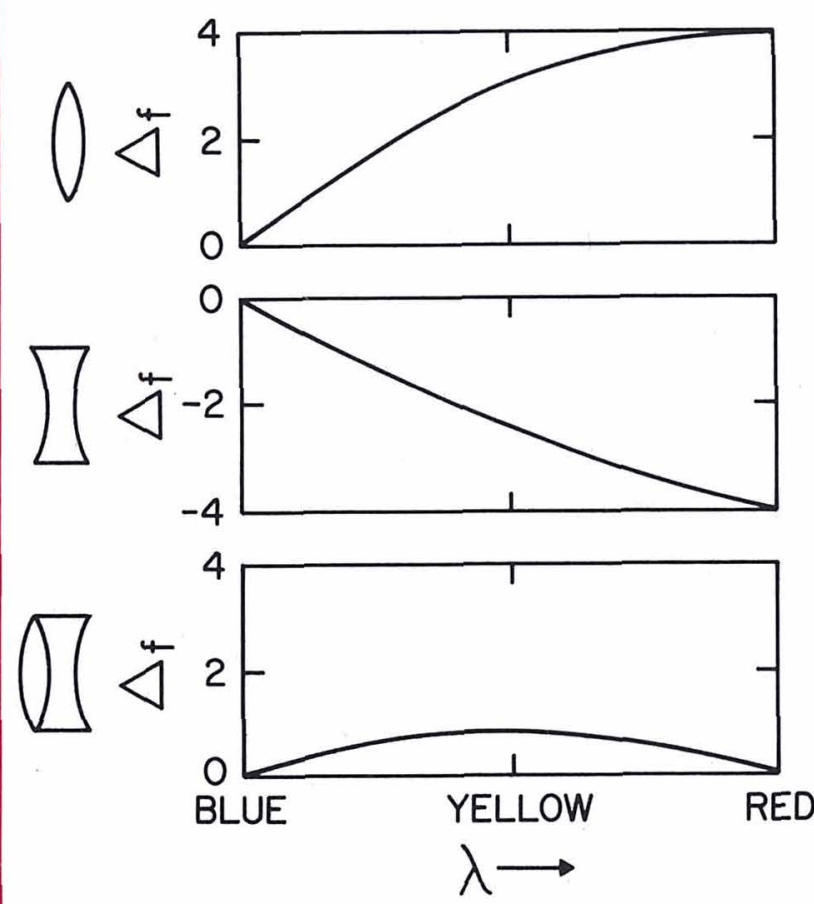

Fig.. 13. Illustrating how a combination of two lenses minimizes the variation of focal length with wavelength.

number of these instrument makers to court to prohibit them from making achromatic telescopes. ${ }^{15}$ They argued that Dollond's patent should be revoked since Hall had invented it before Dollond. However, the court ruled in 1768 that,

It was not the person who locked his invention in his scritoire that ought to profit by a patent for such an invention, but he who brought it forth for the benefit of the public.

Hall never came forward to press a claim and Euler and Klingenstierna probably never made a working achromatic lens.

It is an interesting point that both Euler and Klingenstierna based their ideas of the possibility of making an achromatic lens on the mistaken idea that the eye is achromatic. Since the eye has a glass-like lens surrounded by a water-like fluid, and apparently does not exhibit color fringing, they felt that a glass lens combined with a water lens would be achromatic. The idea persisted for a long time, and even in the early 19th century Barlow made a large telescope using a lens of that construction. But, in fact, the eye is not free of chromatic aberration.

\section{Conclusions}

What conclusions can we draw from these studies?

(1) Technology and science can and often do interact to the benefit of both. The invention of the telescope made many astronomical discoveries possible. On the other hand, knowledge of the nature of color and refraction were necessary for the development of the achromatic lens which made possible the improvement of the telescope.

(2) Authorities cannot always be trusted. Isaac Newton was the world's greatest authority on optics at the time, but his mistaken opinion about the relation between refraction and disperson held up the development of the achromatic lens for half a century.

(3) Unpublished work and unpatented inventions generally go unrewarded. Descartes gave Snell no credit and Dollond never acknowledged the work of Hall. If you make a scientific discovery, even a minor one, publish it and let the world know about it. And if you invent something of use in the world, patent it and get it into production.

(4) Even a "wrong" theory is better than no theory at all. Euler and Klingenstierna's idea that the human eye was achromatic was incorrect, but yet it led them to believe in the possiblity of making a lens free of chromatic aberration.

(5) Amateur scientists can make important contributions to science. Newton did much of his best work while he was a student. Chester Moor Hall was a lawyer, Vitello and Theodoric were monks, Lippershey was a spectacle maker, Dollond was a weaver and instrument maker, and Hevelius was a brewer!

\section{Acknowledgments}

This paper was presented as a talk at Concordia College in Moorhead, Minnesota, on October 11, 1985. The author wishes to thank the staff of the Physics Department there for their invitation. He also wishes to thank his colleague Duane Jaecks for sparking his interest in the history of optics. $\square$

\section{References}

1. Duane H.D. Roller, Am. J. Phys, 49, 206 (1981).

2. L.W. Taylor, Physics, the Pioneer Science (Houghton Miflin, Boston, 1941), p. 498.

3. Olaf Pedersen and Mogens Pihl, Early Physics and Astronomy (Macdonald and Jones, London, 1974), p. 200.

4. Taylor, p. 406

5. Isaac Newton, Isaac Newton's Papers and Letters on Natural Philosophy, edited by I.B. Cohen (Harvard, Cambridge. 1978), p. 47.

6. A Source Book in Medieval Science, edited by Edward Grant, (Harvard, Cambridge, 1974), p. 389.

7. Henry C. King, The History of the Telescope (Dover, N.Y., 1955), p. 31 .

8. Stillman Drake, Telescopes, Tides, and Tactics (Univ. Chicago, Chicago, 1957), p. 19

9. Newton, Papers and Letters, p. 51

10. Isaac Newton, Opticks, 4th ed. (IWm. Innys, London, 1730), reprinted by Dover, New York, 1952l.

11. King, p. 144

12. King, p. 145

13. King, p. 146

14. Peter Dollond. Some Account of the Discovery, made by the Late Mr. John Dollond. F.R.S., which led to the Grand Improvement of Refracting Telescopes (J. Johnson, London, 1789).

15. King, p. 154. 